\begin{tabular}{lll}
\hline & \multicolumn{2}{c}{ Answer } \\
\cline { 2 - 3 } Question & Yes No Did not answer
\end{tabular}

great care in those cases that they perceived as high risk, they still expose themselves to considerable risk from patients not known to be infected with HIV or hepatitis $B$ virus.

Do you think that:

The current guidelines that a patient's permission is always required

before he or she may be tested for HIV antibody are satisfactory?

All high risk patients should be routinely tested for HIV antibody before surgery?

All patients should be tested for HIV antibody before surgery?

\section{5}

628

672

41
402

97

87

39 Surgeons did not answer any part of the question, including the 37 who replied in the pilot study, which omitted this question; 11 answered no to all three parts of the question, and some did not answer all parts of the question.

legal department (personal communication) believes that an employer could be considered negligent for failing to vaccinate or provide proper protective clothing for its employees.

The routine use of double gloves, eye protection, and impervious gowns and immunisation against hepatitis B are simple, easily adopted precautions that considerably reduce the risk of exposure to patients' body fluids. Any further reduction in risk requires more effort by the surgeon and theatre team, particularly for those who handle needles and do not regularly practise a no touch technique. The adoption of such methods will become widespread only when surgeons perceive the risks to which they are exposed as great enough to warrant revision of their operating technique. This does not yet seem to have happened as although most of the respondents to this survey take
I thank my wife, Bridget Porteous, for her invaluable help in conducting this survey.

1 Barker LF, Shulman NR, Murray R, et al. Transmission of serum hepatitis. JAMA 1970;211:1509-12.

2 Rosenburg JL, Jones DP, Lipitz LR, Kirsner JB. Viral hepatitis: an occupational hazard to surgeons. AAMA 1973;223:395-400.

3 Centers for Disease Control. Guidelines for prevention of human immunodeficiency virus and hepatitis $B$ virus to health-care and public-safety workers. MMWR 1989;38(suppl S6):4-5, 31-3.

4 Brough SJ, Hunt TM, Barrie WW. Surgical glove perforations. Br $\mathcal{F}$ Surg 1988;75:317.

5 Hussain SA, Latif ABA, Choudhary AAAA. Risk to surgeons: a survey of accidental injuries during operations. Br f Surg 1988;75:314-6.

6 Matta H, Thompson AM, Rainey JB. Does wearing two pairs of gloves protect operating theatre staff from skin contamination? Br Med f 1988;297:597-8.

7 Duthie GS, Johnson SR, Packer GJ, Mackie IG. Eye protection, HIV, and orthopaedic surgery. Lancet 1988;i:481-2.

8 Brearley S, Buist LJ. Blood splashes: an underestimated hazard to surgeons. Br Med f 1989;299:1315.

Porteous MJLeF. Hazards of blood splashes. Br Med f 1990;300:466.

10 Day LJ. AIDS: an occupational hazard for orthopedic surgeons? Orthop Rev 1989;18:493-7.

11 Jessop JH. Hazards of blood splashes. Br Med f 1990;300:49.

12 Sim AJW, Dudley HAF. Surgeons and HIV. BrMed $\mathcal{F}$ 1988;296:80.

13 British Orthopaedic Association. AIDS and the orthopaedic surgeon. London: British Orthopaedic Association, 1989.

14 Gough HG, Hall WB. A comparison of physicians who did and did not respond to a postal questionnaire. $\mathcal{F}$ Appl Psychol 1977;62:777-80.

15 Denes AE, Smith JL, Maynard JE, Doto IL, Berquist KR, Finkel AJ. Hepatitis $\mathrm{B}$ infections in physicians. fAMA 1978;239:210-2.

$16 \mathrm{Tar}$-Ching AW. Control of substances hazardous to health. $\mathrm{Br} \mathrm{Med} f$ 1989;299:931-2.

(Accepted 20 March 1990)

\title{
Impact of childhood cancer on return to normal schooling
}

\author{
I J Larcombe, J Walker, A Charlton, S Meller, P Morris Jones, M G Mott
}

\section{Cancer Research}

Campaign Education and

Child Studies Research

Group, Department of

Epidemiology and Social

Oncology, Christie

Hospital, Manchester

M20 9QL

I J Larcombe, BSC, research assistant

J Walker, BA, research

assistant

A Charlton, PHD, director

Department of Paediatric Oncology, Royal Marsden Hospital, Sutton SM2 5PT

$S$ Meller, FRCP, consultant paediatrician

\section{Department of Paediatric}

Oncology, Royal

Manchester Children's

Hospital, Manchester

M27 1HA

P Morris Jones, FRCP, reader in child health (paediatric oncology)

Department of Paediatric Oncology, Royal Hospital for Sick Children, Bristol BS2 8BJ

M G Mott, FRCP, reader in paediatrics (oncology)

Correspondence and requests for reprints to: Ms Larcombe.

BrMed f 1990;301:169-71

\begin{abstract}
Most of the research into the psychosocial impact of treatment for cancer in children has concentrated on effects on the family rather than on the children's return to school. Thus parents and teachers were questioned about the problems experienced by 117 children who returned to school after spending time in hospital. The children comprised 51 with cancer and two groups of control children (34 with chronic diseases such as renal disease and cardiac conditions and 32 with orthopaedic conditions such as thoracic scoliosis, club foot, and injuries resulting from trauma). Children in all three groups experienced problems on returning to school, the greatest number and variety occurring in the children treated for cancer and the fewest in the children with orthopaedic conditions. The variety of physical problems was greatest and the variety of academic problems was least, with psychological and behavioural problems intermediate. Several problems seemed to be related to drug treatment. Several children missed a considerable amount of full time education. Many teachers were unsure of the academic expectations and physical capabilities of children returning to school.
\end{abstract}

To facilitate a smooth return to school for a child with cancer improved liaison is needed between the hospital, school, and home during the child's absence and teachers need to be better informed.

\section{Introduction}

Cancer affects one in 10000 children, with about 1200 new cases occurring in Britain annually. ${ }^{1}$ In recent years developments in the treatment of child- l.ood cancer have resulted in substantial improvements in survival rates. Data from the United Kingdom Children's Cancer Study Group, which treats more than three quarters of all childhood malignancy in the United Kingdom, show a five year survival of $63 \%$ for the 1982-3 cohort of 1694 children (O B Eden, personal communication). Most children now return to school at some point during the course of their disease, many doctors recommending that they should do so as soon as possible so that at least part of their lifestyle is normal. The low prevalence of childhood cancers means that few teachers have experience of a child returning to their class after treatment for cancer, and they may be anxious because of lack of knowledge.

Extensive research has been carried out in the United States into the impact of treatment for childhood cancers on school life. ${ }^{2-5}$ In the United Kingdom most research has focused on the effects on the family rather than on the school environment. We studied problems associated with children's return to school with a view to developing material to help those concerned with this transition.

\section{Patients and methods}

We studied 117 children (51 with cancer and 66 controls) who were returning to school after spending time in hospital to identify any problems particular to children returning to school after treatment for cancer. The children with cancer consisted of 36 boys and 15 girls who had been aged 4 to 16 at diagnosis (mean age 9 years 7 months) and who were selected consecutively from ward or hospital registration lists. Children with brain tumours were excluded from the study as they present a special case and will be the subjects of a later 
study. Each child with cancer was matched by age and sex with two children, if-possible, one with a chronic disease $(n=34)$ and one with an orthopaedic condition $(\mathrm{n}=32)$, who formed the control group. The children with chronic disease had renal disease, cardiac conditions, and other chronic illnesses. The children with orthopaedic conditions had been treated mostly during planned admissions for conditions such as thoracic scoliosis, club foot, and injuries resulting from trauma.

Parents and the teachers most concerned with the child's return to school were interviewed by a researcher with a structured questionnaire. They were asked about the physical, academic, psychological, and behavioural problems on the child's return to school. As the study was mainly qualitative results were analysed by content analysis.

\section{Results}

Overall the parents identified more problems than the teachers, though teachers of the children with cancer and those with chronic disease identified more academic problems than parents. For each type of problem (table) the greatest variety of problems mentioned concerned the children with cancer.

Physical problems-Although more children with orthopaedic conditions seemed to have physical problems on their return to school, the range of problems was narrow and related to the practical difficulties of participating in school life with crutches or an arm or a leg in plaster. Most of the problems reported to have been experienced by the children with cancer and those with chronic disease seemed to be directly related to treatments and drugs that they were taking: these included increased appetite, cushingoid appearance, muscle wasting, and various changes in behaviour and mood. Children with cancer also had joint pains, muscle weakness, nausea, mouth ulcers, and other side effects of cytotoxic drugs.

Academic problems - Some children fell behind in all subjects and others fell behind in specific subjects, particularly mathematics and foreign languages. Even after returning to school some children receiving long term maintenance treatment found it difficult to catch up and keep up with subjects that they missed because clinic appointments were on the same day every week. The academic problems of children with chronic disease, particularly those with renal disease, were often described by their teachers as long standing, being the result of repeated bouts of illness and absence from school over several years.

Psychological problems-Various worries were reported for children in all three groups. For those with cancer these included worries about loss of hair and actual or anticipated teasing. For most children many of the worries disappeared on their return to school. For a few children with cancer or with chronic disease, particularly those who had begun renal dialysis or had had a kidney transplant removed, more severe problems of extreme and long term unhappiness were reported.

Behavioural problems - The main behavioural difference between the children with cancer and the other groups was the high proportion of children with cancer who showed negative types of behaviour (table). A minority of parents suggested that their children's drugs might be partly responsible for this behaviour.

Other problems-Children with cancer were absent from school more often than the other children because they had an increased number of episodes of infection, attended hospital for treatment and follow up clinics frequently, and stayed away when outbreaks of chickenpox and measles occurred among classmates. Difficulty in securing transport to and from school was mentioned by a few parents in all three groups.

Education during absence from school-Children are often taught while they are in hospital and may use the home tuition service during convalescence. Several mothers of children in all three groups reported having had difficulties in obtaining appropriate work from the child's school. Almost a quarter of parents from each group had not had but would have liked a home tutor. Difficulties that faced parents included delays in organising home tutors and rulings and guidelines issued by the local education authority on the provision of home tutors. Parents and teachers, however, were agreed on the importance of planning a coordinated programme of work to be followed during the absence from school.

Liaison with teachers before child's return to schoolOnly $13 \%$ of teachers of children with cancer had been contacted by the school health service before the child's return to school. A few teachers would have welcomed more liaison on potential problems. Many teachers of children in all three groups believed that they needed more medical information to give them confidence when dealing with their pupil.

\section{Discussion}

Modern treatments for childhood cancer have transformed this condition into one of many chronic diseases afflicting children. This study supports a suggestion that the school problems of children with cancer can best be seen as part of the general problem of effective schooling for children with chronic diseases. ${ }^{6}$ The problems that occurred and their prevalences in the three groups of children studied suggest that the experiences and needs of children with cancer are most similar to those of children with chronic disease.

The effect of drugs on physical and mental wellbeing has been well documented. ${ }^{7-9}$ Some of the worries identified in this study have been described previously. ${ }^{10}$ In particular, worries about appearance,

Problems experienced by children with cancer, with chronic disease, and with orthopaedic conditions on their return to normal schooling after a period in hospital

\begin{tabular}{|c|c|c|c|}
\hline & Children with cancer & Children with chronic disease & $\begin{array}{l}\text { Children with } \\
\text { orthopaedic conditions }\end{array}$ \\
\hline Physical problems & $\begin{array}{l}\text { Tiredness }(65 \%) \text {, mobility }(30 \%) \text {, muscle and joint } \\
\text { pains }(24 \%) \text {, handwriting }(12 \%) \text {, change in } \\
\text { appearance, prostheses, gait/balance, } \\
\text { coordination, nausea, weight gain }\end{array}$ & $\begin{array}{l}\text { Tiredness }(65 \%) \text {, slowness, change in } \\
\text { appearance, weight gain }\end{array}$ & Plaster casts, crutches \\
\hline Academic problems & $\begin{array}{l}\text { Falling behind }(51 \%) \text {, concentration ( } 29 \%) \text {, worry about } \\
\text { school work }\end{array}$ & $\begin{array}{l}\text { Falling behind }(32 \%) \text {, concentration } \\
(26 \%)\end{array}$ & Falling behind $(41 \%)$ \\
\hline Psychological problems & $\begin{array}{l}\text { Worry about: physical appearance, health and future, school } \\
\text { work }(47 \%) \text {; emotional fragility }(33 \%)\end{array}$ & $\begin{array}{l}\text { Worry about: physical appearance, } \\
\text { health and future }(32 \%) ; \text { emotional } \\
\text { fragility }\end{array}$ & $\begin{array}{l}\text { Worry about physical } \\
\text { appearance }(19 \%)\end{array}$ \\
\hline Behavioural problems & $\begin{array}{l}\text { Negative behaviours: aggression, tantrums, irritability, } \\
\text { defiance }(45 \%) \text {; withdrawal }\end{array}$ & Negative behaviour $(26 \%)$ & Negative behaviour (13\%) \\
\hline Other problems & $\begin{array}{l}\text { Increased infections, forced absences, frequent } \\
\text { appointments, transport, dietary, work sent home }\end{array}$ & Transport, dietary, work sent home & Transport \\
\hline
\end{tabular}


return to school, and catching up on missed work were found in all three groups. A recent report by the Department of Education and Science indicates the need for rapid identification of children, in hospital and at home, who would benefit from home tuition and for coordination of the educational services available to them. ${ }^{11}$

One recurrent suggestion was that improved liaison between all the parties would improve reintegration into school. Eiser maintained that closer liaison between the school and hospital would be advantageous, ${ }^{12}$ and Checkryn et al emphasised the importance of frequent exchanges of information between the health care team and teachers. ${ }^{4}$ We found that most teachers of children with cancer were fairly well informed about their pupils' illness, but they would have liked more medical information and an indication of potential problems; like Fowler et al we found that teachers of children with chronic disease and with orthopaedic conditions were less well informed about the health of their pupils. ${ }^{13}$

Many teachers suggested that the school health service could play a more active part in liaising between the hospital and school. This might be facilitated by reducing the delay in sending discharge letters to general practitioners, who would then be able to inform school medical officers earlier. ${ }^{14}$ An information pack similar to that produced for general practitioners could be prepared for senior clinical medical officers to help them liaise with schools. ${ }^{\text {is }}$

Nowadays children receiving treatment for cancer do not have to be kept away from school because of outbreaks of chickenpox or measles unless these occur in their own classroom. Once the child has been given an injection of varicella zoster immunoglobulin or normal immunoglobulin he or she should return to school immediately. Consultants could vary the day of clinic appointments for children receiving long term maintenance treatment and so avoid repeated loss of the same lessons.

Finally, if teachers are to be better prepared on the individual needs of their pupils they must be made aware of potential physical, academic, psychological, and behavioural problems.

We thank the Cancer Research Campaign for funding this study and the consultants, teachers, and families who took part.

1 Draper GJ, Stiller CA. Cautious optimism. Paediatric Nursing 1989;1:22-4 2 Deasy-Spinetta P, Spinetta JJ. The child with cancer in school. Am f Pediatr Hematol Oncol 1980;2:89-94.

Ross JW. Resolving non-medical obstacles to successful school re-entry for children with cancer. I Sch Health 1984;54:84-6.

4 Checkryn J, Deegan M, Reid J. Impact on teachers when a child with cancer returns to school. Children's Health Care 1987;15:161-5.

5 Spinetta JJ, Deasy-Spinetta P. The patient's socialization in the community and school during therapy. Cancer 1986;58:512-5.

6 Cyphert FR. Back to school for the child with cancer. I Sch Health 1973;43:215-7.

7 Muggia FM, Louie AC, Sikie BI. Pulmonary toxicity of antitumour agents. Cancer Treat Rev 1983;10:221-43.

8 Gellinger K. Pathologic effects of chemotherapy. In: Valker MD, ed. Oncology of nervous systems. Boston: Nijhoff, 1983:285-340.

9 McHaney VA, Thibadoux G, Hayes SA, Green AA. Hearing loss in children receiving cisplatin chemotherapy. F Pediatr 1983;102:314-6.

0 Henning J, Fritz GK. School. re-entry in childhood cancer. Psychosomatics 1983;24:261-9.

1 Department of Education and Science. Education observed II: hospital and home education services. Pudsey: DES, 1989.

12 Eiser C. How leukaemia affects a child's schooling. British foumal of Social and Clinical Psychology 1980;19:365-8.

13 Fowler MG, Johnson MP, Atkinson SS. School achievement and absence in children with chronic health conditions. F Pediatr 1985;106:683-7.

14 Penney TM. Delayed communication between hospitals and general practitioners: where does the problem lie? Br Med F 1988;297:28-9.

15 James JA, Harris DJ, Mott MG, Oakhill A. Paediatric oncology information pack for general practitioners. Br Med f 1988;296:97-8.

(Accepted 17 April 1990)
What does the description jitter factor mean when used in connection with electromyography?

Conventional electromyography studies the response of a motor unit, which is defined as a group of muscle fibres innervated by a single neurone. Refinement of this using a suitable electrode allows recording from single fibres. If the response from two adjacent fibres is recorded in normal subjects a difference in latency of up to $50 \mu$ s is commonly found. A larger discrepancy in disease might be due to block of axon conduction, delay at the neuromuscular junction or muscle fibre, or slowing of conduction velocity. This variation between fibres is known as jitter. The technique is time consuming and requires particular care in interpretation.

Increased jitter is found in myasthenia and is useful in the diagnosis of mild cases. It is also shown when reinnervation is occurring. Abnormalities are to be expected in a variety of diseases of nerve and muscle. Jitter is useful for clinical purposes in early diagnosis but the findings are nonspecific and must be interpreted in relation to the clinical condition.BRYAN ASHWORTH, consultant physician, Edinburgh

Halliday AM, Butler SR, Paul R. A textbook of clinical neurophysiology. Chichester: Wiley, 1987. Stâlberg E, Tronteli J. Single fibre electromyography. Woking: Miravelle Press, 1979

\section{What is the most suitable antidepressant drug for patients with epilepsy?}

Depression is one of the most frequently encountered psychiatric problems in patients with epilepsy. All antidepressant drugs that are not monoamine oxidase inhibitors and some that are lower the seizure threshold, ${ }^{1}$ so the use of antidepressants in patients with epilepsy is a common clinical dilemma. Among the routinely prescribed and clinically most effective antidepressants there is little evidence in practice to support claims of the superiority of any one compound over another in terms of effects on seizure threshold. Newer antidepressants, particularly selective 5-hydroxytryptamine reuptake inhibitors, have not yet been adequately evaluated in these patients. As no particular antidepressant can be considered hazard free in patients with epilepsy the specific choice of antidepressant should be dictated by factors akin to those in other patients.

Careful and frequent supervision of patients with epilepsy who start antidepressant drugs is mandatory, with hospital admission indicated in those with poor seizure control or those at risk of status epilepticus. Some evidence suggests that the rate of introduction of antidepressant treatment is an important factor in precipitating seizures. ${ }^{2}$ Compounds should be started at a minimal dose followed by incremental increases. $-\mathrm{R}$ J DOLAN, consultant psychiatrist, London

1 Edwards JG. Antidepressants and convulsions. Lancet 1979;ii:1368-9.

Toone BK, Fenton GW. Epileptic seizures induced by psychotropic drugs. Psychol Med 1977;7:265-70

\section{Are welders at risk of developing rodent ulcers?}

The spectrum of light produced by welding, especially arc welding, does contain ultraviolet light, mostly ultraviolet B but some ultraviolet A, the exact quantity and quality depending on the type of welding and the gas and metal used. It is this radiation that causes welder's blepharoconjunctivitis, which is prevented by the wearing of adequate goggles. The likelihood of developing skin cancer provoked by ultraviolet light would be enhanced in those welders who have the appropriate skin type - that is, those who do not tan well on exposure to ultraviolet light, whether ultraviolet $\mathrm{A}$ or ultraviolet $\mathrm{B}$, and those who do not wear adequate protection for their skin either in the form of a hood, visor, clothing, or sunscreen.

Chronic exposure to radiation is considered to be the cause of many but not all rodent ulcers. It is difficult to quantify the risk from welding because the particular area of skin exposed to the ultraviolet light produced while welding is likely to be exactly the same as that exposed to the sun's ultraviolet light rays on everyday outdoor exposure, and the proportionate exposure would be virtually impossible to assess.-ALAN B SHRANK, consultant dermatologist, Shrewsbury 